UDC: $811.134 .2 ' 374.4$

DOI: https://doi.org/10.18485/beoiber.2018.2.1.2

\author{
Petr Stehlík ${ }^{1}$ \\ Universidad Masaryk de Brno \\ República Checa
}

\title{
DELIMITACIÓN DE LA COMPOSICIÓN EN ESPAÑOL DESDE EL PUNTO DE VISTA SEMÁNTICO²
}

\begin{abstract}
Resumen
En el presente artículo se examinan de manera sistemática los principales aspectos semánticos que intervienen en la delimitación de los compuestos del español frente a las palabras derivadas (prefijadas o sufijadas) y las unidades fraseológicas. Nuestro objetivo es demostrar que el criterio semántico resulta importante, si no crucial, para determinar la naturaleza de no pocas formaciones limítrofes, pero que, al mismo tiempo, la gradualidad de las oposiciones semánticas respectivas y la inevitable subjetividad en su interpretación desaconsejan otorgar a dicho enfoque una validez absoluta.
\end{abstract}

Palabras clave: español, composición, delimitación, criterios semánticos.

\section{DELIMITATION OF COMPOUNDING IN SPANISH FROM THE SEMANTIC PERSPECTIVE}

\begin{abstract}
The article systematically examines the main semantic aspects intervening in the delimitation of Spanish compounds against derived (prefixed or suffixed) words and phraseological units. Our goal is to demonstrate that the semantic criterion is important, if not crucial, for determining the character of numerous borderline lexical units, but, at the same time, that the gradualness of the semantic oppositions in question and the inevitable subjectivity in their interpretation discourage ascribing absolute validity to this approach.
\end{abstract}

Key words: Spanish, compounding, delimitation, semantic criteria.

1 stehlik@phil.muni.cz

2 Este artículo se basa parcialmente en una investigación más amplia, cuyos resultados fueron publicados en el libro Problém delimitace nékterých slovotvorných postupů a prostředkù ve španělštině (Stehlík 2016; disponible solo en checo). 


\section{Introducción}

Aunque el concepto de composición en cuanto al mecanismo lexicogenético pueda parecer suficientemente claro y unívoco (se forman palabras nuevas mediante la combinación de dos o más lexemas libres o trabados; véanse, p. ej., Varela Ortega 2005, NGLE 2009, Buenafuentes de la Mata 2010, Aguirre 2013), las dificultades con que se encuentran los lingüistas a la hora de determinar el estatuto de las raíces cultas (temas, afijoides) por una parte, y delimitar con precisión los ámbitos de la composición y la fraseología, por otra, ponen de manifiesto la borrosidad de los límites entre los principales procedimientos de formación de palabras y hacen cuestionar la propia concepción discreta de las categorías lingüísticas. En este artículo intentamos señalar la relevancia y, a la vez, la relatividad del criterio semántico para la delimitación de los compuestos del español, centrándonos primero en el estatuto problemático de las bases cultas, o sea, los prefijoides y sufijoides, y examinando después (en el apartado 3 ) los límites poco nítidos entre los compuestos sintagmáticos y los fraseologismos nominales, sobre todo en relación con el escurridizo concepto de idiomaticidad.

\section{Composición culta vs. derivación}

En principio, la estructura semántica de los compuestos formados por dos bases grecolatinas (p. ej.: geología, aeródromo) o por un tema culto unido a una palabra autóctona (aeropuerto, biodiversidad, rumorología, etc.) no se diferencia sustancialmente de la que presentan las palabras derivadas mediante prefijos y sufijos (con excepción de los apreciativos), es decir, determinante + determinado, por lo que no cobra mayor relevancia en los debates acerca del estatuto de los llamados afijoides (el término más usado para referirse a las bases cultas hasta finales del siglo XX). La principal dificultad en la delimitación de los morfemas derivativos con respecto a las bases compositivas concierne al significado léxico de los propios afijoides, que tienen mayoritariamente su origen en sustantivos y adjetivos del griego o el latín.

Mientras que no pocos morfemas ligados procedentes de adjetivos (p. ej.: macro-, micro-, equi-, homo-, iso-, neo-, paleo-) pueden clasificarse como prefijos gracias a su significado abstracto, que encaja en alguna de las categorías semánticas preestablecidas (tamaño, igualdad, dimensión temporal, etc.), otros elementos antepuestos que también provienen de adjetivos (como hagio- o necro-) poseen rasgos semánticos mucho más específicos y son considerados temas o bases compositivas por la mayoría de los morfólogos españoles. Ahora bien, lo que llama nuestra atención es que dicho criterio no parece tener casi ninguna relevancia en el caso de los elementos pospuestos. En este contexto, conviene recordar que fue ya Alba de Diego (1983: 20) quien advertía, en su famoso artículo "Elementos prefijales y sufijales: iderivación o composición?", sobre "el mismo funcionamiento" de dos morfemas sufijales con significado más o menos idéntico 
(y relativamente específico): el sufijo -itis (p. ej.: neuritis) y el sufijoide / base compositiva -algia (neuralgia) ${ }^{3}$. Sin embargo, el ejemplo único de -oide (del gr. cĩó 'forma' y con el equivalente -forme), considerado en el DRAE (2017) como elemento compositivo en el sentido de 'parecido a', 'en forma de', pero como sufijo apreciativo cuando aporta a la palabra base un matiz despectivo (p. ej.: mongoloide, negroide, feminoide) demuestra que la existencia de una categoría semántica adecuada puede facilitar el reconocimiento de la función derivativa a un elemento originalmente compositivo también en el ámbito de la sufijación, a pesar de las marcadas diferencias en la clasificación de los afijos antepuestos y pospuestos. Como es sabido, todos los grupos de prefijos fueron establecidos a partir del criterio semántico (prefijos de tamaño, lugar, tiempo, etc.), mientras que los sufijos se clasifican tradicionalmente según la categoría gramatical de las palabras creadas con ellos (sufijos nominales, adjetivales, etc.), con excepción de los apreciativos, divididos, a su vez, en sufijos diminutivos, aumentativos y peyorativos.

No obstante, el hecho de que en el inventario de los sufijos del español casi no haya morfemas que tengan su origen en una palabra con significado pleno no puede achacarse solo a la heterogeneidad clasificatoria arriba señalada (es decir, la división de los prefijos según un criterio puramente semántico frente a la clasificación de los sufijos en función de los criterios léxico-categorial y semántico), sino que es una consecuencia natural - aunque cuestionable - de la diferente prioridad que se otorga, en los ámbitos de la prefijación y la sufijación, a todavía otro criterio hasta ahora no mencionado (y casi nunca abiertamente declarado), a saber, el etimológico-categorial ${ }^{4}$. Hablando más concretamente, la barrera casi infranqueable al respecto consiste en el origen nominal de la raíz culta ${ }^{5}$, así que, en la práctica, las consideraciones sobre el nivel de abstracción o concreción de su contenido semántico entran en juego solo cuando se trata de un elemento antepuesto procedente de un adjetivo (compárense, p. ej., los prefijos hetero-, micro-, neo- con las bases compositivas hagio-, necro-, xeno-). Al mismo tiempo, es obvio que el inventario de los sufijos del español está formado casi exclusivamente por morfemas que funcionaban como afijos ya en el latín o el griego, independientemente de

\footnotetext{
${ }^{3}$ Esta asimetría afecta también a los morfemas -sis y -patía (p. ej.: nefrosis, nefropatía).

4 Para más información sobre la relevancia de los diferentes criterios de delimitación en el campo de la prefijación, véase Stehlík (2011: 50-55, 59-64).

${ }^{5} \mathrm{El}$ argumento central a favor del carácter derivativo de las bases grecolatinas fue que "los elementos de este tipo de construcción [...] tienden a desempeñar la función de prefijos o sufijos en lugar de funcionar como primero o segundo elemento del compuesto. Se liberan así del modelo etimológico que les dio nacimiento para pasar a depender del modelo funcional. [...] Una vez, pues, independizados de sus formaciones de origen, se comportan como verdaderos afijos..." (Alba de Diego 1983: 18). En contra, Martín García (2017) afirma tajantemente que "no hay prefijos sustantivos" (Martín García 2017: 87) y que "solo los elementos que modifican como adjetivos o adverbios son susceptibles de gramaticalizarse. Los elementos que modifican como sustantivos [...] no se gramaticalizan y forman compuestos (hidroterapia, dermoprotector)..." (Martín García 2017: 92).
} 
sus propiedades semánticas específicas ${ }^{6}$. Como excepción podemos mencionar el morfema -mente (de origen nominal, pero no culto), que suele incluirse entre los sufijos del español precisamente con el argumento de que tiene significado categorial. Por otra parte, el elemento adjetival -forme no deja de ser, en opinión de la mayoría de los lingüistas españoles, una base compositiva, y ello a pesar de que en la $N G L E$ (2009: 563) se emplea el término sufijo para referirse a su equivalente -oide no solo al ser utilizado con valor apreciativo, sino también cuando conserva su significado primario de 'semejanza'. En otras palabras, a diferencia de la prefijación, donde se observa claramente la prioridad del criterio etimológico-categorial sobre el semántico, en el caso de la derivación sufijal no puede establecerse ninguna jerarquía similar y las características semánticas de los morfemas pospuestos (significado categorial o apreciativo vs. significado específico) se toman en consideración solo ad hoc y de una manera muy arbitraria. Así, los únicos elementos de origen léxico catalogados mayoritariamente como sufijos son -mente, -oide e - ificar, lo que pone en evidencia la asimetría en el tratamiento de las bases cultas (los prefijoides y los sufijoides) en la morfología española, al igual que una relevancia muy limitada del criterio semántico para separar los mecanismos de la derivación y la composición.

\section{Compuestos sintagmáticos nominales vs. fraseologismos nominales}

Al menos desde los años 80 del siglo pasado (véase Bustos Gisbert 1986), la formación de las unidades léxicas pluriverbales constituye, en el marco de la morfología léxica, un tipo de composición particular cuya delimitación con respecto al campo de la fraseología es sumamente problemática. Aunque se han propuesto numerosas pruebas de fijación morfosintáctica (Bustos Gisbert 1986: 62; Almela 1999: 136-138; Zuluaga 1980: 97-98, Corpas Pastor 1996: 23-24, Alonso Ramos 2009: 250-253) que pueden aplicarse tanto a los compuestos sintagmáticos como a los fraseologismos (para diferenciarlos, a su vez, de las combinaciones libres de palabras), los resultados obtenidos con ellas muestran inequívocamente una fuerte interrelación entre el grado de cohesión semántica y la fijación formal de los sintagmas lexicalizados. Por tanto, a continuación vamos a centrarnos en las propiedades semánticas de las unidades plurilexemáticas, siendo nuestro objetivo evaluar la importancia de este aspecto en la delimitación que nos ocupa7.

En marcado contraste con las unidades fraseológicas, cuya clasificación y subclasificación se fundamentan - parcial o completamente - en el enfoque semántico (véanse, p. ej., Corpas Pastor 1996, Ruiz Gurillo 2001, Alonso Ramos 2009), la distinción

${ }^{6}$ Hasta hace relativamente poco, la sufijación representaba, de acuerdo con la tradición lingüística hispánica, el único mecanismo derivativo, en tanto que los prefijos eran considerados elementos compositivos. A nuestro parecer, puede tratarse de uno de varios factores que explican este fenómeno.

${ }^{7}$ En la práctica, este problema atañe casi exclusivamente a la distinción entre los compuestos y los fraseologismos nominales.

BEOIBERÍsTICA Vol. II / Número 1 (2018) | 27-36 
de los principales dos tipos de compuestos (los propios/léxicos/ortográficos y los sintagmáticos) descansa, ya tradicionalmente, sobre un criterio puramente formal (la fusión gráfica de los primeros frente a la autonomía de los constituyentes de los segundos). Dicho esto, conviene añadir de inmediato que los compuestos sintagmáticos y los fraseologismos suelen definirse, de manera casi idéntica, como unidades léxicas pluriverbales con significado unitario ${ }^{8}$, lo que dificulta la separación nítida entre ellos. Además, en relación con la cohesión semántica de los sintagmas lexicalizados se manejan, en sentidos diversos, también términos tan ambiguos como unidad referencial e idiomaticidad, cuyo significado y alcance trataremos de esclarecer en los apartados siguientes.

\subsection{Unidad semántica y referencial}

A diferencia de lo que podemos observar en la zona de transición entre la composición y la derivación, el análisis semántico de los compuestos sintagmáticos y los fraseologismos no enfoca solo el significado de los constituyentes aislados, sino, principalmente, la cohesión semántica de las expresiones pluriverbales resultantes. No obstante, y como apunta acertadamente García-Page (2008: 111), dicha cohesión puede identificarse sea con la idiomaticidad del sintagma fijo, sea con su función designativa, o con ambas características a la vez. Este último caso se ve claramente en Val Álvaro (1999: 4765), quien explica que, "semánticamente, los compuestos no resultan de la simple adición de los rasgos de sus constituyentes. El compuesto lleva consigo la formación de un concepto unitario que permite la designación de una realidad específica". De ahí también el frecuente uso combinado de los términos unidad semántica y unidad referencial en las definiciones de las expresiones fijas, el cual, desgraciadamente, confirma la imposibilidad de prescindir de criterios extralingüísticos en el estudio de las unidades plurilexemáticas.

Según intentaremos demostrar en el apartado 3.2, la idiomaticidad no es, ni mucho menos, un rasgo diferenciador fiable para delimitar con nitidez los compuestos sintagmáticos y los fraseologismos, con lo que aumenta la potencial relevancia al respecto de la función denominativa o designativa (explicada con claridad en la cita de Val Álvaro del párrafo anterior) $y$, estrechamente vinculada a ella, de la unidad referencial de los sintagmas nominales fijos. Fue precisamente este criterio el que sirvió a Montoro del Arco (2008: 136-137) para establecer dos "polos opuestos del campo de las FNP": 1) los fraseotérminos, que son, en su mayoría, términos especiales con función denominativa ( $y$ que coinciden, más o menos, con los compuestos sintagmáticos tradicionales); y 2) las locuciones nominales, o sea, unidades idiomáticas que suelen funcionar en la oración

8 Del significado unitario de las expresiones plurilexemáticas nominales hablan tanto numerosos autores de trabajos sobre formación de palabras (p. ej.: Bustos Gisbert 1986, Lang 1992, Miranda 1994, Val Álvaro 1999, Varela Ortega 2005) como los fraseólogos españoles (Casares 1950, Zuluaga 1980, Corpas Pastor 1996, García-Page 2008, etc.). 
como atributo para "caracterizar a un individuo [...] o, más frecuentemente, una situación..." (Montoro del Arco 2008: 137).

El problema es, según García-Page (2008: 113), que igualmente las locuciones nominales cumplen, en cierto sentido, una función denominativa (aunque solo secundaria) ${ }^{9}$; y en cuanto a una supuesta mayor expresividad y rasgos connotativos de los fraseologismos en comparación con los términos básicos y los compuestos, el lingüista citado (García-Page 2008: 113) relativiza incluso esta distinción: "también la palabra compuesta [...] representa una fórmula altamente expresiva al ser una estructura semántica sintética que con frecuencia incorpora valores connotativos" (p. ej.: perro salchicha, cama nido). De todas formas, García-Page menciona, en la misma página, todavía otro contraste entre los compuestos sintagmáticos y las locuciones, basado en la concreción o abstracción del referente (a diferencia de las locuciones, la mayoría de los compuestos tienen un referente concreto ${ }^{10}$. Este criterio - sin validez absoluta, por cierto - nos lleva de vuelta a la dificultad que hemos adelantado al comienzo del presente apartado, o sea, al hecho de que es imposible encontrar un rasgo distintivo puramente lingüístico que separe los compuestos y los fraseologismos nominales; pero como se verá más adelante, algunos factores extralingüísticos contaminan también el concepto de idiomaticidad, del que nos ocuparemos pormenorizadamente a continuación.

\subsection{Idiomaticidad}

Ya Zuluaga (1980: 121), uno de los clásicos de la fraseología española, advertía que "el término idiomático no es unívoco y claro", y después de repasar las concepciones anteriores de idiomaticidad, llegó a establecer tres características básicas del funcionamiento idiomático: 1) las expresiones fijas se componen de unidades léxicas autónomas (palabras), 2) estos constituyentes no tienen identidad semántica propia y 3) forman "con los demás componentes de la expresión fija una unidad de sentido" (Zuluaga 1980: 124). Siempre, según el mismo autor, los puntos arriba mencionados implican varios otros rasgos de idiomaticidad señalados por diferentes lingüistas, concretamente el sentido no composicional, la ausencia de motivación secundaria, la inseparabilidad del significado (los sintagmas fijos "significan en bloque") y la estructura formal y semánticamente irregular de las expresiones pluriverbales (Zuluaga 1980: 124).

Quizás el único de los fraseólogos españoles que no solo constató la vaguedad del término significado idiomático, sino que asimismo intentó dilucidar las causas de las

9 Sin embargo, García-Page (2008: 113) pone también ejemplos de locuciones a las que no corresponde ninguna denominación primaria uni- o pluriverbal, como son cajón de sastre o conejillo de Indias.

10 "[E]s abrumadora la cantidad de compuestos que se han acuñado para designar nuevas realidades que representen seres o entes físicos, sensibles, concretos (frente al escaso número de locuciones con esta característica), y son, en cambio, escasos los compuestos nominales que designan referentes abstractos (ideas, sentimientos, virtudes, defectos, actitudes, propiedades de los objetos, etc.)." (García-Page 2008: $113)$. 
discrepancias definitorias y clasificatorias existentes, fue García-Page (2008: 26-29), quien llamó la atención sobre la identificación errónea de la idiomaticidad, por parte de no pocos autores, con solo alguno de sus aspectos, sea este el empleo de al menos un elemento de la construcción fija en sentido figurado o la no composicionalidad de la expresión fija, entendida por determinados lingüistas como la presencia de un rasgo semántico implícito dentro de la unidad pluriverbal. Así, Alonso Ramos (2009: 257) clasifica la formación pasta de dientes, a primera vista composicional (y considerada generalmente un compuesto sintagmático), como una cuasi-locución porque contiene el significado implícito de finalidad, y Mendívil Giró (2009: 104) interpreta, a su vez, la expresión leche condensada como una colocación simplemente por implicar algunas cualidades específicas no explicitadas de la sustancia en cuestión (color, textura, dulzura, etc.) ${ }^{11}$. Estos ejemplos bastan para ver que el margen de subjetividad en el análisis semántico de las unidades pluriverbales es, hoy por hoy, demasiado amplio. Por ello, García-Page (2009: 28) tiene razón cuando escribe que “la determinación de la idiomaticidad y el establecimiento de los estadios intermedios de la misma por criterios objetivos, empíricos, es aún una asignatura pendiente", pero, en tal caso, la validez de las clasificaciones de fraseologismos que se basan, total o parcialmente, en el grado de idiomaticidad de las expresiones fijas (p. ej.: Alonso Ramos 2009; Ruiz Gurillo 2001) queda completamente en entredicho.

Otro problema es que el sentido no composicional u opaco de cualquier unidad léxica - incluso de una palabra derivada - viene confundido por algunos lingüistas con el significado fraseológico, como si la idiomaticidad fuera una propiedad exclusiva de los frasemas, aunque, por una parte, "no todas las UFS son idiomáticas, pues se trata de una característica potencial, no esencial, de este tipo de unidades" (Corpas Pastor 1996: 27) ${ }^{12}$; $y$, por otra parte, hay muchas palabras derivadas o compuestas (p. ej.: lavadora, aguardiente) semánticamente opacas o con significado figurado que, obviamente, no solo por ello tienen que ser clasificadas como fraseologismos. Un ejemplo extremo de la engañosa sinonimia de los adjetivos idiomático y fraseológico lo constituye la clasificación semántica de fraseologismos de Alonso Ramos (2009: 262), en la que aparecen como frasemas (colocaciones, cuasi-locuciones, semi-locuciones o locuciones completas) también compuestos univerbales (nochevieja, girasol, matasellos, aguardiente, etc.) y palabras derivadas ("frasemas morfológicos", p. ej.: lavadora, hombrera).

Dejando a un lado la ya mencionada subjetividad en la interpretación de la idiomaticidad y volviendo a la cuestión de la delimitación de los ámbitos de la

${ }^{11}$ De acuerdo con esta concepción de idiomaticidad, tendríamos también que asumir que todos los compuestos semánticamente exocéntricos (p. ej.: año luz = 'distancia'; piel roja = 'persona'; sacacorchos = 'instrumento') son fraseologismos. Sobre la tipología de los compuestos exocéntricos, véase Zacarías Ponce de León (2015).

12 No pueden considerarse idiomáticas sobre todo las locuciones prepositivas y conjuntivas como por encima de, con el fin de que, para que, etc., cuyo significado (muy transparente) no es, además, léxico. 
composición y la fraseología, la mayor objeción que se puede hacer al análisis semánticoreferencial ${ }^{13}$ de los sintagmas nominales fijos queda muy bien resumida en las palabras de Mendívil Giró (2009: 101): "En el momento en el que un SN adquiere valor denominativo, automáticamente pierde composicionalidad". Ahora bien, si esto es cierto y si a la hora de valorar el grado de idiomaticidad de las unidades léxicas complejas con función designativa no resulta posible prescindir de conocimientos enciclopédicos o extralingüísticos, quizás deberíamos admitir que el criterio de idiomaticidad es completamente inservible, pues en el sentido más amplio de este término, ningún compuesto sintagmático ( $\mathrm{y}$, por supuesto, tampoco un compuesto gráfico o una palabra derivada) encierra en sus elementos explícitos todas las propiedades de la realidad designada.

\section{Conclusiones}

A lo largo de este artículo nos hemos ocupado de las principales modalidades del criterio semántico que son utilizadas, en combinación con otros criterios formales, para delimitar el procedimiento de la composición frente a la derivación y con respecto al campo de la fraseología. Según hemos observado, sus deficiencias radican tanto en la gradualidad de las oposiciones semánticas en cuestión (significado abstracto vs. concreto; significado idiomático vs. composicional o literal), como en la contaminación del criterio semántico por el enfoque referencial (unidad semántica y referencial; idiomaticidad vs. composicionalidad).

La única variante de dicho criterio que parte de una perspectiva puramente lingüística está relacionada con el estatuto de los temas cultos o afijoides, aunque su aplicación sistemática queda restringida, en la morfología española actual, a las raíces prefijas de origen adjetival. En cuanto a la problemática combinación de dos criterios heterogéneos - aunque estrechamente relacionados entre sí - uno lingüístico (el semántico) y otro extralingüístico (el referencial), esta entra en juego sobre todo en la delimitación de los compuestos y fraseologismos nominales frente a las combinaciones libres de palabras, al igual que (pero con resultados mucho menos convincentes) para separar los ámbitos de la composición y de la fraseología. Como hemos visto, el mayor escollo consiste en la imposibilidad de determinar el grado de cohesión semántica de un sintagma nominal fijo sin tomar en cuenta la realidad extralingüística designada, cuyas propiedades no explicitadas - y casi siempre hay algunas - permiten extender el polémico concepto de idiomaticidad (o "fraseologicidad") a prácticamente todo compuesto sintagmático.

A modo de conclusión, podemos constatar que el denominador común de todas las variantes del criterio semántico arriba descritas es la precariedad de las oposiciones en

${ }^{13}$ La heterogeneidad de este criterio fue señalada en el apartado anterior.

BEOIBERÍsTICA Vol. II / Número 1 (2018) | 27-36 
las que se fundamentan, la cual, junto con el empleo asistemático del enfoque semántico en el campo de la formación de palabras en general, deja un margen no desdeñable para la subjetividad del lingüista.

\section{BIBLIOGRAFÍA}

Aguirre, Carmen. Manual de morfología del español. Barcelona: Castalia, 2013. Impreso. Alba de Diego, Vidal. "Elementos prefijales y sufijales: ¿derivación o composición?". Emilio Alarcos Llorach et al. (eds.), Serta Philologica F. Lázaro Carreter, 1, Madrid: Cátedra, 1983: 17-21. Impreso.

Almela Pérez, Ramón. Procedimientos de formación de palabras en español. Barcelona: Ariel, 1999. Impreso.

Alonso Ramos, Margarita. "Delimitando la intersección entre composición y fraseología”. LEA, 31/2 (2009): 243-275. Impreso.

Buenafuentes de la Mata, Cristina. La composición sintagmática en español. San Millán de la Cogolla: Cilengua, 2010. Impreso.

Bustos Gisbert, Eugenio. La composición nominal en español. Salamanca: Ediciones de la Universidad de Salamanca, 1986. Impreso.

Casares Sánchez, Julio. Introducción a la lexicografía moderna. Madrid: CSIC, 1969 [1950]. Impreso.

Corpas Pastor, Gloria. Manual de fraseología española. Madrid: Gredos, 1996. Impreso.

García-Page Sánchez, Mario. Introducción a la fraseología española: Estudio de las locuciones. Barcelona: Anthropos, 2008. Impreso.

Lang, Mervyn Francis. Formación de palabras en español. Madrid: Cátedra, 1992. Impreso.

Martín García, Josefa. "Los límites de la prefijación". Jesús Pena (ed.), Procesos morfológicos. Zonas de interferencia, Verba, Anexo 76, Santiago de Compostela: Universidade de Santiago de Compostela, 2017: 77-104. Impreso.

Mendívil Giró, José Luis. "Palabras con estructura externa". Elena de Miguel Aparicio (ed.), Panorama de la lexicología. Barcelona: Ariel, 2009: 83-113. Impreso.

Miranda, José Alberto. La formación de palabras en español. Salamanca: Ediciones Colegio de España, 1994. Impreso.

Montoro del Arco, Esteban Tomás. "Relaciones entre Morfología y Fraseología: las formaciones nominales pluriverbales". Ramón Almela Pérez y Esteban Tomás Montoro del Arco (eds.), Neologismo y morfología, Murcia: Universidad de Murcia, 2008: 121-146. Impreso.

Real Academia Española. Diccionario de la lengua española. Edición del Tricentenario. Actualización 2017. Web. 3 Dec. 2017. [DRAE] 
Real Academia Española y Asociación de Academias de la Lengua Española. Nueva gramática de la lengua española. Madrid: Espasa Libros, 2009. Impreso. [NGLE]

Ruiz Gurillo, Leonor. Las locuciones en español actual. Madrid: Arco / Libros, 2001. Impreso.

Stehlík, Petr. Aspectos problemáticos de la prefijación en español. Brno: Masarykova univerzita, 2011. Impreso.

-. Problém delimitace některých slovotvorných postupi̊ a prostředku ve španělštině. Brno: Masarykova univerzita, 2016. Vytištěno.

Val Álvaro, José Francisco. "La composición”. Ignacio Bosque y Violeta Demonte (eds.), Gramática Descriptiva de la Lengua Española. Vol. 3. Madrid: Espasa-Calpe, 1999: 4757-4841. Impreso.

Varela Ortega, Soledad. Morfología léxica: La formación de palabras. Madrid: Gredos, 2005. Impreso.

Zacarías Ponce de León, Ramón. “Compuestos metonímicos en español. ¿Exocentricidad o predicación de punto de referencia?». Onomázein, 32 (2015): 62-79. Web. 3 Dec. 2017.

Zuluaga Ospina, Alberto. "La fijación fraseológica". Thesaurus, 30 (1975): 225-248. Impreso.

—. Introducción al estudio de las expresiones fijas. Frankfurt: Peter D. Lang, 1980. Impreso. 